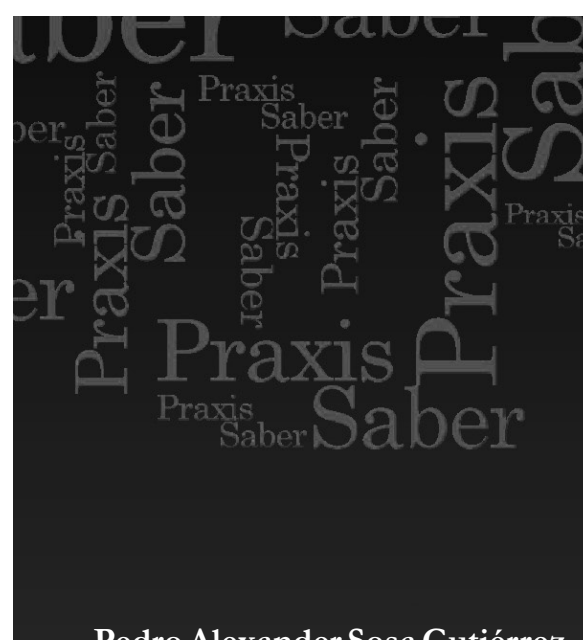

Pedro Alexander Sosa Gutiérrez

Universidad Pedagógica y

Tecnológica de Colombia

alexsosagz@gmail.com

Elver Chaparro Cardozo

Universidad de Boyacá

echaparro@uniboyaca.edu.co

Artículo de Investigación

Recepción: 15 de noviembre de 2013 Aprobación: 9 de junio de 2014

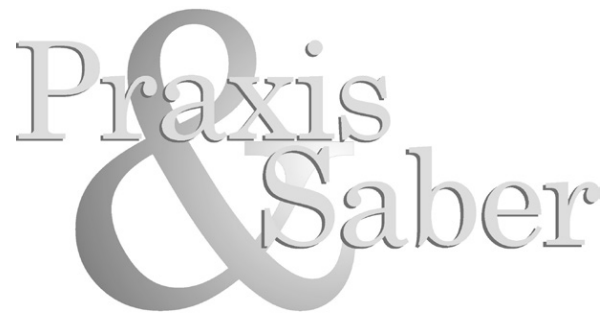

Revista de Investigación y Pedagogía Maestíáa en Educación. Uptc

\section{REGÍMENES ESCÓPICOS, DISCIPLINAMIENTO Y SUJETOS. LA EDUCACIÓN ARTÍSTICA EN LA ESCUELA COLOMBIANA ${ }^{1}$.}

\section{Resumen}

Se describen las condiciones de emergencia de la Educación Artística en el sistema escolar colombiano a finales del siglo XVIII y comienzos del siglo XIX como un proceso de apropiación de los discursos ilustrados propios de la modernidad. A partir de ello se describen regímenes escópicos o modos de ver que se constituyen en una forma de producción de lo visual movilizados por la escuela; siendo este un hallazgo transversal de esta búsqueda que evidenció cuatro momentos del proceso de apropiación de la Educación Artística en Colombia: 1. El discurso ilustrado de Pedro Rodríguez de Campomanes sobre la educación popular en artes con el propósito de reformar los gremios artesanales; 2. La creación de una relación arte-ciencia durante la Expedición

1 El presente texto es una síntesis de la tesis de Maestría en Educación titulada 'Emergencia de la Educación Artística en la escuela colombiana: regímenes escópicos, disciplinamiento y sujetos", que mantuvo un interés histórico por la conformación de la Educación Artística en el sistema escolar colombiano; la cual se resolvió desde una perspectiva arqueológica genealógica. 
Botánica y la fundación de talleres de dibujo; 3. La creación del sistema de instrucción pública republicano con la difusión del sistema lancasteriano con propósitos utilitaristas; y 4. La difusión de manuales de dibujo geométrico y la introducción de la enseñanza objetiva (métodos pestalozzianos).

Palabras clave: Educación Artística, regímen escópico, institucionalización, arqueología, genealogía.

\section{Scopic Regimes, Discipline, And Subjects. ARTS EDUCATION IN COLOMBIAN SCHOOL}

\section{Abstract}

The paper describes the conditions in which Arts education emerges in the Colombian school system at the end of $18^{\text {th }}$ century and the beginning of $19^{\text {th }}$ century as a process of taking ownership of Enlightenment discourses belonging to Modernity. Based on that, it describes scopic regimes -understood as points of view that become a production way of the visual thing mobilized by school, since it is a cross-cutting find in this search which showed four stages in the process of introducing Arts education in Colombia: 1. Pedro Rodríguez de Campomanes' Enlightenment discourse on popular education in Arts aimed at transforming craft guilds; 2 . The creation of a relationship between Arts and science during the Botanical Expedition and the establishment of drawing workshops; 3 . The creation of the Republican public instruction system with the promotion of Lancasterian system with utilitarian purposes. 4. The circulation of geometrical drawing manuals and the introduction of objective teaching (Pestalozzian methods).

Keywords: Arts education, scopic regime, institutionalization, archaeology, genealogy.

\section{RÉgimes Scopiques, Discipline Et Sujets. L'Éducation Artistique Dans Les Écoles COlOMBIENNES}

\section{Résumé}

Les situations d'urgence dans l'éducation artistique du système scolaire colombien á la fin du XVIIIème siècle et au commencement du XIXème siècle sont décrites comme un processus d'appropriation des discours 
illustrés propres à la modernité. Sur cette base l'on décrit les régimes scopiques ou les manières de voir qui se constituent comme une forme de production du visuel mobilisé par l'école; ceci étant une découverte transversale de cette recherche qui met en évidence quatre moments du processus d'appropriation de l'éducation artistique en Colombie: 1. Le discours illustré de Pedro Rodríguez de Campomanes sur l'éducation populaire dans l'art dans le but de réformer les corps de métiers d'artisanat; 2. La création d'une relation art-science durant l'Expédition Botanique et la fondation d'ateliers de dessin; 3. La création du système d'instruction publique républicain avec la diffusion du système lancastérien ayant des objectifs utilitaristes; et 4. La diffusion de manuels de dessin géométrique et l'introduction de l'enseignement objectif (méthodes pestalozziennes).

Mots clés: éducation artistique, régime scopique, institutionnalisation, archéologie, généalogie.

\section{Regimes Escópicos, Disciplinamento E Sujeitos. A EduCAÇÃO ArTística nA EscOLA COLOMBIANA}

\section{Resumo}

Descrevem-se as condições de emergência da educação artística no sistema escolar colombiano as finais do século XVIII e começos do século XIX como um processo de apropriação dos discursos ilustrados próprios da modernidade. A partir daquilo se descrevem regimes escópicos o modos de ver que se constituem em uma forma de produção do visual mobilizados pela escola, sendo isto um achado transversal desta procura que evidenciou quatro momentos do processo de apropriação da educação artística na Colômbia: 1. O discurso ilustrado de Pedro Rodríguez de Campomanes sobre a educação popular em artes com o intuito de reformar os grêmios artesanais; 2. A criação de uma relação arte-ciência diante a Expedição Botânica e a fundação de oficinas de desenho; 3. A criação do sistema de instrução pública republicano com a difusão do sistema lancasteriano com propósitos utilitaristas; e 4. A difusão de manuais de desenho geométrico e a introdução do ensino objetivo (métodos pestalozzianos).

Palavras chave: educação artística, regime escópio, institucionalização, arqueologia, genealogia. 


\title{
Introducción
}

\author{
"El poder produce; produce realidad; \\ produce ámbitos de objetos y rituales de verdad. \\ El individuo y el conocimiento que de él se puede obtener \\ corresponden a esta producción".
}

(Foucault, 2005: 198)

La Educación Artística en diferentes momentos se ha pretendido como formadora de sujetos que entienden sobre los aspectos estéticos y sensibles, como posibilidad para reconocer y representar el mundo, tal como lo requiere la modernidad, donde el adiestramiento de la mano, la mirada y el cuerpo, serían cualidades que exigió la estéril industria, que demandaron formas de visualidad y formas de ver establecidas.

De esta forma la Educación Artística ha pasado por delimitaciones conceptuales normatizadas y normalizadas que la trasladan, instalan y reubican como un saber escolar con diferentes propósitos. Al iniciar esta investigación identificamos preliminarmente algunos axiomas sobre la conformación de la Educación Artística, de los cuales nos hemos distanciado posteriormente, siendo estos: 1 La Educación Artística como una posibilidad para pertenecer al sistema productivo, (Jhon Dewey); 2) Educación Artística para la creatividad y la autoexpresión (Arnheim, Rudolf); 3) Educación Artística para el desarrollo de la percepción y la alfabetización visual, (María Acaso); 4) Educación Artística para la comprensión crítica y la contemplación, (Elliot W. Eisner); y 5) La Educación Artística para la creación artística (Herbert Read). Estas formas de ver y entender la Educación Artística están soportadas en intereses cargados de conceptualizaciones sobre las formas de ser de la enseñanza del arte 'desde el afuera', pues consideran el saber escolar desde abstracciones teóricas de la escuela y de la enseñanza del arte.

Por otro lado, entender la enseñanza del arte en la escuela como una práctica-discursiva, supone que ésta posee unos dominios y métodos que la instalan como un saber no específico que se define en sus prácticas, y comprende que se ha constituido a partir de discursos tanto cercanos como ajenos a ésta; y tiene como esfera de conformación la escuela. Así, delimitar la concepción de la Educación Artística en esta investigación, intentó identificar si ella se ha concebido para la formación, para la creación artística o para formar el carácter sensible de los sujetos 
(educación para el arte); para ser un complemento del universo de los saberes acumulados por la humanidad, o una educación con el arte; para proteger, mantener, conservar unos oficios establecidos como lenguajes del arte, o una educación en el arte.

Estas tres diferencias se deben tener en cuenta porque de ellas depende la institucionalización de ciertas prácticas y saberes. En primer lugar, la educación para el arte, no sólo reconoce al individuo como un ser creativo sino que le da interés a la mirada como forma de contemplación, en donde todo su ser se compromete; en esta forma de la educación del arte se procura cultivar el espíritu sensible con el objetivo de ser consumidor de arte. En segundo lugar, la educación con el arte, estaría cimentada en el valor que puede tener éste como un complemento y ligado al reconocimiento de las formas propias de ser de las expresiones artísticas, su historia y sus formas de producción; que se apoya en un ejercicio de creación que procura la creatividad para desenvolverse en diferentes circunstancias. En tercer lugar, la educación en el arte, fundada en las dinámicas de producción y circulación de lo considerado como arte en una época determinada.

Es así que la enseñanza del arte en muchas ocasiones se ha estudiado desde los valores, los conceptos y creencias del arte. Por otro lado, la Educación Artística a la cual atiende este documento, no es una Educación Artística concebida como un saber auxiliar del arte o una transposición de los saberes del arte para la escuela. Es decir, no es una Educación Artística que ubique su saber en el arte, por el contrario, su saber proviene de su propia práctica y de las discursividades que atraviesa la escuela. Es de esta manera como la Educación Artística se convierte en una formación discursiva considerada como una tecnología escolar que permite la conformación de un tipo de sujeto. Del mismo modo delimita sus saberes a partir de las configuraciones y frecuencias en un momento histórico determinado.

De tal manera se asume como una práctica y un saber escolar que ha conservado en su quehacer la enseñanza y distribución de conocimientos fundados en las técnicas primeras de la expresión plástica (dibujo, pintura, escultura, grabado, modelado). Asimismo, debemos aclarar que nuestra preocupación es una aproximación histórica a su estudio, desarrollo y transformación en el sistema escolar colombiano. Estas dos aclaraciones tienen sentido pues la enseñanza del arte en la actualidad se ha posicionado en lugares distintos a la escuela y reúne otras disciplinas de las bellas artes. 


\section{Elecciones de método}

Historiar la enseñanza del arte en la escuela requirió establecer una revisión diferencial entre las transformaciones de la política educativa, las prácticas de los maestros y la conformación de subjetividades; por esta razón apostamos por una mirada de cortes históricos, los cuales permitieron ubicar acontecimientos fechables, localizables y descriptibles de la formación de un saber y su práctica, los cuales nos ayudaron a establecer un marco diferencial frente a la historia lineal. Esta lectura buscó estudiar la institucionalización en dos espacios: la institución y el sujeto. De esta forma los procesos de apropiación e institucionalización de los saberes de la Educación Artística en Colombia constituyeron el punto de partida para entender las condiciones en que aparece este saber en el sistema escolar colombiano. Esto conllevó una aproximación metodológica que se trazaría desde los aportes del francés Michel Foucault, en las contingencias de indagación que nos dan la Arqueología y la Genealogía como herramientas metodológicas; donde lo arqueológico rastrea los vestigios posibilitadores de determinadas prácticas educativas, y lo genealógico como aquella comprensión de las condiciones en las cuales dichos vestigios se institucionalizaron o se apropiaron, como prácticas legitimadas, es decir:

Inscribir, en la dinámica particular de una sociedad, cualquier producción técnica o de saber proveniente de otra cultura y generada en condiciones históricas particulares. Apropiar evoca modelar, adecuar, retomar, coger, utilizar, para insertar en un proceso donde lo apropiado se recompone porque entra en una lógica diferente de funcionamiento. Apropiar un saber es hacerlo entrar en las coordenadas de la práctica social. Es, por tanto, un proceso que pertenece al orden del saber como espacio donde el conocimiento está accionado por mecanismos de poder y no por la lógica del movimiento de los conceptos en el conocimiento científico (Sáenz, Saldarriaga \& Ospina, 1997: XIV).

En esta medida, la aproximación que hacemos del concepto apropiación, no sólo resulta ser una recepción de determinados saberes y métodos, sino aquellos dispositivos de saber-poder, prácticas y discursos posibilitadores de los saberes asociados a la Educación Artística en el sistema escolar colombiano.

Esta aproximación implicó la conformación de un archivo y la realización de lecturas minuciosas tanto de fuentes primarias como 
secundarias, la identificación de regularidades discursivas, el desarrollo de escrituras descriptivas, tematizaciones y organización de materiales, con el presupuesto permanente de hacer una aproximación paciente y documentalista.

Este material fue rastreado en los siguientes lugares: Archivo Regional de Boyacá, Biblioteca Luis Ángel Arango, Biblioteca Nacional, Colegio de Boyacá, Escuela Normal de Varones y Fondo Posada de la Universidad Pedagógica y Tecnológica de Colombia. Además repositorios digitales como "Internet Archive" y el Centro de Investigación MANES; por otro lado, diferentes tipos de documentos como periódicos, artículos, avisos, manuales, diarios, entre otros. Posteriormente se realizaron lecturas que permitieran la aproximación a los documentos así:

\begin{tabular}{|c|c|}
\hline LECTURAS & CARACTERÍSTICAS \\
\hline $\begin{array}{l}\text { Lectura } \\
\text { temática }\end{array}$ & $\begin{array}{c}\text { Caracteriza las temáticas de los discursos emergentes que consolidaron los saberes de la } \\
\text { educación artística. }\end{array}$ \\
\hline $\begin{array}{c}\text { Lectura } \\
\text { discursiva }\end{array}$ & $\begin{array}{c}\text { Sitúa el texto en correspondencia con otros discursos, modelos pedagógicos y corrientes de } \\
\text { pensamiento aparentemente foráneas y sin concordancia con ellos. }\end{array}$ \\
\hline $\begin{array}{l}\text { Lectura } \\
\text { crítica }\end{array}$ & $\begin{array}{c}\text { Comprende los discursos sobre la Educación Artística y su importancia dentro de la escuela } \\
\text { así como los mecanismos de apropiapión y sus prácticas de dominación, adiestramiento y } \\
\text { vigilancia. }\end{array}$ \\
\hline $\begin{array}{l}\text { Lectura } \\
\text { icónica }\end{array}$ & $\begin{array}{l}\text { Hace referencia a la función de la imagen en el texto como facilitador en la comprensión de } \\
\text { un contenido, así como la posibilidad de establecer las regularidades del establecimiento de } \\
\text { un régimen de visualidad a través de la Educación Artística. }\end{array}$ \\
\hline
\end{tabular}

Estas lecturas son retomadas del libro pedagogía e historia. La historicidad de la pedagogía, la enseñanza, un objeto de saber (Olga Lucia Zuluaga Garcés, 1999).

\section{La ilustración, la escolarización y los regímenes de visualidad}

Los procesos educativos se han considerado históricamente como escenarios privilegiados para la producción de subjetividad. Siendo entonces la Educación Artística, para los nacientes Estados nacionales, un mecanismo de doble beneficio; por un lado, hacer parte del proyecto moderno del nuevo ciudadano y, por otro, orientar al sujeto hacia un mundo racional en función del progreso y la utilidad. En este sentido, la concepción de modernidad supone no sólo la apertura a cambios paulatinos y transformaciones sociales históricas, sino también a un ejercicio de la actividad racional, científica y tecnológica. Esta modernidad 
se traduce en un proceso de secularización donde el fundamento teológico es reemplazado por el relato científico; por tanto, la noción de modernidad está vinculada con el de racionalización y de constitución de una sociedad racional: "De manera que la racionalización, componente indispensable de la modernidad, se convierte por añadidura en un mecanismo espontáneo y necesario de la modernización" (Touraine, 2000: 18).

Estas condiciones permitieron que la ilustración constituyera un tipo de sujeto racional orientado por una moral civil en función del proyecto moderno; que traería consigo el establecimiento de un poder que trasciende la soberanía para instalarse en los dominios de la producción, la utilidad y los valores democráticos, que irrumpen en la definición de un tipo de sujeto, modelado y ajustado a esta nueva visión del progreso, la ciencia y la razón.

Cabe advertir que en la Ilustración la razón no era sólo el eje central, sino que añadido a esto, aparece una inquietud por las artes y el mundo de las sensaciones, el conocimiento adquirido por vía de los sentidos, tal como ya lo habían hecho los empiristas, pero que tales sensaciones podrían orientarse mediante un ejercicio racional. Estaríamos por lo tanto ante una forma de institucionalización del saber construido a través de las sensaciones.

De esta forma, la preocupación por regular aquellas sensaciones primarias fue una de las inquietudes del proyecto ilustrado pero, sobre todo, la incorporación de estos discursos en la escuela, el cómo encauzar dichas sensaciones en función de lo útil. Por tal razón el redescubrimiento de la infancia y una formación basada en la naturaleza y los sentidos se convierte en el nuevo fundamento de la educación; de tal forma que esta preocupación por el uso racional frente a lo sensible orienta la educación al proyecto moderno de la ilustración, donde aquellas impresiones sensibles y goce estético hacen parte de esta visión productiva en la escuela.

De tal forma que en la constitución de la Educación Artística, 'el ver' se hace fundamental para la comprensión del mundo, es así que se ven implicados aquellos saberes provenientes directamente de las ciencias, como aquellos que intentaron explorar las sensaciones y la experiencia 
estética, determinantes en la configuración de un régimen escópico ${ }^{2}$ o modo de ver.

Para Martin Jay históricamente se han configurado determinados regímenes escópicos, los cuales han constituido campos de fuerza o elementos que se hallan yuxtapuestos; que definen determinadas prácticas de ver que se institucionalizan. El primero de estos regímenes escópicos corresponde al perspectivismo cartesiano, el cual fundamenta las artes visuales con el redescubrimiento de la perspectiva. El segundo régimen se asocia con el mundo empírico baconiano, donde ya no existe una referencia a un espacio geometrizado, a las semejanzas. Por tanto este segundo régimen corresponde a una experiencia visual de tipo experimental que se orienta a la observación. Por último describe un régimen visual que denomina "barroco" donde éste no responde simplemente al estilo de un período, sino a un régimen que coexiste con los dos anteriores en el decurso de la modernidad.

Estos tres regímenes escópicos puede decirse que aparecen superpuestos en la constitución de la Educación Artística y la escolarización, los cuales pueden ser ubicados desde la invención del Orbis Sensualium Pictus hasta el sistema de enseñanza mutua y objetiva desarrolladas por Lancaster y Pestalozzi respectivamente, donde se describen regímenes de visualidad trasladados a la escuela e incorporados a prácticas escolares; donde "ver" y "saber" responden a mirar al modelo y repetirlo, ya que ver es aprender para luego grabarlo en la memoria. Esto supone que el modelo "perspectivismo cartesiano" imperó en la educación del arte como dispositivo de regulación de la mirada que, desde Comenio a Pestalozzi, se pondría en juego el problema de la atención y fijación del conocimiento a través de la imagen en los manuales escolares. Así, el ver, comienza a ser el régimen que se instituye, y emprende una fuerte batalla entre palabra e imagen, luego que la primera abordaría apenas la superficie de las cosas, mientras la segunda evidenciaría su apariencia externa, siendo el Orbis, ese dispositivo que privilegiaría el deleite del ojo a través de las diversas láminas que acompañan el texto para afinar lo visual; este sistema se

2 El término régimen escópico o régimen de visualidad alude a un cierto tipo de ver y representar de una sociedad en una época determinada, en función de las diversas condiciones históricas, culturales y epistemológicas. Por lo tanto el régimen escópico permite que por medio de la mirada se privilegie la comprensión vía ocular, es decir, se diferencia lo visto de lo no visto, lo apropiado para una instancia histórica determinada. 
mantuvo hasta Pestalozzi y permitió ajustar la educación de la percepción y de los sentidos.

Esta propuesta del Orbis conduce a una cultura de la imagen en la escolarización, pero sobre todo al desarrollo de una cultura de la atención en Occidente, tal como lo describirá ampliamente Martin Jay ${ }^{3}$ cuando realiza un estudio histórico de la atención como problema de la percepción visual en la modernidad, siendo entonces el Orbis ese dispositivo de visualidad que permite captar la atención del niño, pero fundamentalmente para formarlo en función de un interés utilitario. Por lo tanto se promueve en el niño un escenario en el cual pueda redescubrir la naturaleza, revelada a través del mundo sensible, "los sentidos"; pero esto implicaba que esa naturaleza pudiera ser dominada y ordenada, y esto demandaba una serie de métodos de enseñanza en función de la gran mayoría, es decir, enseñar todo a todos, donde el método pueda inducir a la 'verdad'.

Para el caso de la Educación Artística, Comenio comenzaba a ocupar un lugar significativo con su ya conocida Didáctica Magna, donde reunió y sistematizó su experiencia como pedagogo en las escuelas de su comunidad religiosa, ubicando las artes al lado de las ciencias, el lenguaje y la moral. Particularmente en esta obra señala el método de enseñanza adecuado en cada caso, destinando el capítulo XXI al Método de las Artes, enmarcado en el ámbito de la utilidad y la intuición con finalidades prácticas, donde describe el uso de modelos e instrumentos de trabajo en actividades como la carpintería, y otros de su misma naturaleza, que se asemejaban al del mundo antiguo y del Medioevo; donde la categoría "artista" era una noción intercambiable con la de artesano.

Ya en el Siglo de las Luces Rousseau y Pestalozzi se enfocan en función del modelo de la naturaleza, donde se realiza un estudio empírico y directo, estableciendo una relación entre naturaleza, individuo, observación y conocimiento activo de las cosas, un régimen empírico. Rousseau por su parte plantea un retorno a la naturaleza, donde lo bello es producto de la imitación, siendo el arte —y particularmente el dibujo_-, el medio por el cual se puede reproducir la realidad, contribuyendo a una formación del ojo y de la mano. Las ideas de Rousseau son materializadas en Pestalozzi en la medida que estructura un sistema de enseñanza basado

3 Ver: Suspensión de la percepción de Martin Jay. 
en la intuición de la naturaleza (régimen escópico empírico), siendo éste el fundamento verdadero de la instrucción humana; de tal forma que la intuición tenía como propósito la ordenación del mundo y la orientación de la percepción de los niños. Por tal motivo la intuición demanda determinadas acciones contemplativas que permitan ordenar los objetos en función de sus similitudes, lo cual ayuda y guía al niño para conocer el mundo y entenderlo sistemáticamente.

Esta fijación y atención mediante el dibujo contribuye a los tres elementos pestalozzianos: forma, número y nombre, siendo éstos los fundamentos de la intuición, luego que la imagen sensible del mundo tiene valor por sí misma y la imagen rehúye a las retículas, y mas bien con las impresiones y formas de la naturaleza, que se conectan con la forma (dibujo, geometría), número (aritmética) y, por último, nombre (aprendizaje lingüístico). Elementos que pueden verse descritos en su $A B C$ de la intuición, en el cual revela el procedimiento, donde se obliga al niño a dibujar inicialmente líneas horizontales, en seguida líneas verticales, posteriormente ángulos rectos, curvas, entre otros, siendo este mecanismo un aprestamiento antes de consentir dibujar algo que tenga algún tipo de significado para el niño.

De tal manera que la aproximación a los objetos sensibles del mundo no se da directamente en la copia de una organización naturalista, sino mas bien en reconocer en ella una estructura, es decir, una gramática implícita en las formas que percibe el niño de la naturaleza, por lo tanto esta primera aproximación del dibujo no está en función del arte mismo sino en función de la escritura y la geometría, puesto que implicaba comprender las longitudes y las medidas.

Esta relación transversal entre la Educación Artística y la modernidad y los regímenes de visualidad, permite mostrar la correlación entre el proyecto moderno, la escolarización del arte, las prácticas de subjetivación y los intereses civilizatorios. Así se presenta cómo la escolarización de la enseñanza del arte respondió a los objetivos de la modernidad, identificando intereses diversos como la razón, el progreso y la experiencia estética.

4 Aclaramos que esta visión geométrica no es la correspondiente al perspectivismo cartesiano como ficción, como estructura del espacio visual, sino que responde a las formas, las cosas y la naturaleza. 


\section{Apropiaciones de la enseñanza del arte en Colombia y los regímenes de visualidad}

La escolarización de la Educación Artística en el contexto nacional estuvo permeada en primera instancia por las aspiraciones del proyecto moderno de la Ilustración, junto a variadas tensiones políticas y sociales por las cuales atravesaba la sociedad colonial de finales del siglo XVIII e inicios del siglo XIX. Esto llevó a la apropiación de un sistema basado en la utilidad, el progreso y el dominio de las poblaciones; principios civilizatorios que fueron determinantes para los nacientes Estados nacionales. En tal sentido, la Ilustración comprendió la universalización de la educación y su respectiva democratización, lo que requería de una cierta regulación, normalización y sistemas disciplinarios eficientes.

Esto permitió que, por influencia de la Ilustración, se institucionalizara un tipo de enseñanza que paulatinamente superaba la educación doméstica en función de la instrucción, siendo ésta enmarcada en el ámbito de lo público; la cual tenía como finalidad la transmisión de conocimientos útiles en función del nuevo hombre ciudadano, privilegiando el estudio de la naturaleza, la razón y la fe.

Asentadas las bases de la instrucción y la culminación del período colonial en Hispanoamérica y los nacientes procesos independistas a inicios del siglo XIX, se establecieron una serie de reformas políticas, culturales, económicas y educativas que, por efecto de las reformas borbónicas en España, conllevaron a la expulsión de los Jesuitas, generando cambios drásticos en el tipo de enseñanza e incorporando un sistema de instrucción pública fundamentado en discursos asociados a la utilidad y el progreso; la instrucción era "[...] uno de los instrumentos más idóneos para el progreso de las naciones" (Orlando \& Noguera, 2002: 7), pero sobre todo, el establecimiento de prácticas policivas o acciones de gobierno sobre la población, las cuales buscaban intervenir en la vida civil a través de mecanismos como los censos, campañas de higienización y todo aquello que implicara una determinada forma de regulación y disciplinamiento. La educación retoma estos mecanismos en función de una transformación del antiguo orden en la conciencia del nuevo ciudadano para cristalizar en sus virtudes la utopía republicana. Era la materialización del ideario moderno que pretendía transformar el viejo orden para lograr "la felicidad, el progreso, el bienestar" de la patria mediante la transformación de la población en "ciudadanos útiles". De muchas formas se repetían en 
los discursos las propuestas de la Enciclopedia y de la Ilustración, pero "con las dificultades de la fundación de un nuevo orden de iguales en una sociedad profundamente desigual” (García Sánchez, 2007: 187)

Es así que identificamos cuatro momentos o hitos del proceso de apropiación de la Educación Artística en Colombia y su conexión con los regímenes de visualidad, siendo estos: 1) el discurso ilustrado (Campomanes) sobre la educación popular en artes con el propósito de reformar los gremios artesanales; 2) la creación de una relación artesciencias durante la Expedición Botánica y la fundación de talleres de dibujo; 3) La creación del sistema de instrucción pública republicano con la difusión del sistema lancasteriano con propósitos utilitaristas; y 4) la difusión de manuales de dibujo geométrico y la introducción de la enseñanza objetiva (métodos pestalozzianos).

\section{El discurso ilustrado de Campomanes sobre la educación popular}

Identificamos una primera fase de apropiación de discursos provenientes de la incorporación de los desarrollos educativos de la península en la Nueva Granada, especialmente los promovidos por las industrias populares, las cuales tuvieron como estandarte los aportes de Pedro Rodríguez de Campomanes, quien a través de sus famosos discursos ${ }^{5}$ sobre la industria y la educación popular de los artesanos, tenía como meta la recuperación de la economía del reino; en ellos Campomanes evidencia un particular interés en la enseñanza moderna de las artes y los oficios, cuyo propósito fuese el de fomentar la creación de las industrias populares adecuadas al nuevo cambio de la Ilustración y en función de la regeneración de las clases populares y de higienización de las mismas, como lo podemos evidenciar en el 'Discurso sobre la educación popular de los artesanos y su fomento'. Por lo tanto, el discurso de Campomanes buscaba legislar, instruir, legitimar y hacer de los oficios un campo productivo enfocado a la utilidad y práctica de artes y oficios, que tenía ya un asidero en las ideas

5 Son estos el 'Discurso sobre el fomento de la industria popular' de 1774 y el 'Discurso sobre la educación popular de los artesanos y su fomento' de 1775, publicados en España, donde se ofrecían pautas para orientar la educación de los artesanos. 
de la Ilustración, sobre todo por el 'reformismo Borbónico', donde se inicia un proceso en el cual se aboga por la generación de fuerzas productivas que incentivaron un carácter práctico y racionalista de la Educación Artística.

Con el advenimiento de estas nuevas tecnologías de administración de las poblaciones por parte del Estado, el 'Discurso sobre la educación popular de los artesanos y su fomento', cumple con el objetivo, no sólo de reorganizar el sistema artesanal, sino de administrarlo y volverlo productivo en función del proyecto modernizador y del desarrollo económico; dicho discurso plantea una regulación del sistema de las artes a través de planteamientos que se traducen en orden público, ley natural y educación, siendo entonces este sector el que comienza a ser sometido bajo regímenes de dominación.

Estos antecedentes en la formación de los oficios en el mundo colonial nos lleva a pensar en una clara diferenciación entre oficio y arte, demarcando dichos umbrales, pero sobre todo en función de una estratificación, un sistema subordinado que para el caso de las artes "comprenden las ciencias especulativas, y a todos los oficios prácticos, que constan de reglas, porque unos y otros conocimientos necesitan ayudarse del artificio de ellas y de las demostraciones." - Y más adelante afirma— "Por artes sólo entiendo a las que necesitan de reglas y aprendizaje" (Campomanes, 1775: 12).

En tal sentido la pertinencia de las artes revela un interés práctico y utilitario, como bien lo describe Antonio de Pedro:

La historia de los oficios, según las apreciaciones de Campomanes, formaría parte de la misma historia de las artes. Es decir, lo que se habría producido a lo largo de la historia de las artes manuales es una lucha por conquistar un nuevo nivel de conocimiento, una nueva legitimidad social que les permitiese "alejarse" desde aquellos tempranos inicios que se habían caracterizado por la "rudeza de experiencias y observaciones"; ya en tiempos de la Ilustración, en actividades guiadas por "reglas" (más o menos complejas, según el caso de cada oficio) que ameritaban de un aprendizaje y de una enseñanza especializada (De pedro Robles, 2009: 126).

6 Dichas reformas aparecen con la dinastía de los borbones que inicia con Felipe V (1701-1746), sigue con Fernando VI (1746-1759) y se fortalece con Carlos III, donde se ubica Pedro Rodríguez de Campomanes. 
Estos avances de la Educación Artística comienzan a ser reveladores para el naciente sistema de instrucción pública, "la escuela", donde las estrategias desarrolladas en el artesanado van a cobrar un valor importante en la formación de la infancia, gracias a la apropiación de discursos lancasterianos y pestalozzianos en la educación colombiana, ubicando la educación de los sentidos a través de la normalización, en un lugar estratégico para el proyecto moderno de nación.

\section{La mirada objetiva: arte y ciencia en la expedición botánica}

Para el proyecto civilizatorio de la modernidad se estableció una centralidad en el sentido de la vista, que desde el Renacimiento y la Revolución Industrial hizo posibles inventos como la imprenta, la perspectiva y la fotografía, fomentando una primacía de lo visual y determinando modos de ver que regularon y normalizaron la mirada.

Dichos regímenes de visualidad apelaban a la constitución de un determinado poder, evidenciando formas en las cuales se comportaba la percepción visual, e institucionalizando un régimen disciplinario del ver mediante técnicas apropiadas para el proyecto ilustrado a través de las cuales se ejercía un poder sobre la mirada. Por lo tanto, la imagen aparece como el aparato descriptivo-visual que cobra un papel protagónico en el proyecto científico. Así, "la visualización del conocimiento que llevó a cabo la Ilustración a través de la invención de innovados paradigmas visuales - evidentemente llevados a cabo en grabados y libros ilustrados más que en pinturas y esculturas - invitaban a la participación interactiva a un enorme espectro de espectadores" (Stafford, 1997: 60).

En el proyecto ilustrado la noción de enciclopedia correspondía a la de dar o revelar una idea mediante el uso de la imagen, donde la relación entre arte y conocimiento estaba a medio camino con el libro ilustrado; aspecto que no sería extraño en América, si ponemos en evidencia la tradición de ilustradores de la Real Expedición Botánica de la Nueva Granada, la cual hace parte de la estrategia del gobierno borbónico de la Ilustración y de la racionalización de la enseñanza, donde el botánico de la expedición, con su mirada entrenada, podía taxonomizar las especies. Las imágenes o ilustraciones no apelaban al sentimiento estético del observador, sino mas bien a la racionalidad analítica del científico, donde la función específica del dibujante consistía en resaltar aquellos elementos 
necesarios para la taxonomización, la cual se constituye en una 'formación discursiva" que define un régimen de visualidad para la Nueva Granada; siendo éste el caracterizado como baconiano o empírico, que respondía a estos nuevos intereses de un conocimiento adquirido por medio de la visión, una epísteme escópica fundamentada en la experiencia, donde los sentidos ratifican la verdad de las cosas.

De este modo, con Mutis se puede identificar un tipo de formación artística con características utilitarias y racionales que implicaban tanto la organización de la naturaleza como su clasificación, siendo ésta una tarea de la ciencia natural del siglo XVIII y XIX que involucraba la taxonomización y representación visual, donde la naturaleza se hacía transportable, lo cual implicaba la definición de reglas para sistematizar y estandarizar la observación, un método objetivo centrado en el ejercicio cuidadoso de la mirada y la atención. Tal sistema permite evidenciar un tipo de formación centrada en el ojo, un régimen escópico que demanda poner la mirada en función de la ciencia.

\section{Creación del sistema de instrucción pública republicano y la difusión del sistema lancasteriano con propósitos utilitaristas}

En ese sentido y posterior a la tarea de Mutis, en cuanto a la formación artística, se crea la necesidad de un sistema de instrucción pública que promoviera la cristalización de la utopía republicana, en función del ideario moderno, enfocado a la formación de sujetos útiles.

Aunque este paso del mundo colonial al republicano supuso una transición en determinadas prácticas de enseñanza, se conservaron algunas de tipo doméstico, donde prevalecía la preceptoría; sin embargo, lo que realmente marcaría una gran diferencia sería el establecimiento de las escuelas de primeras letras, junto con la aparición de un nuevo tipo de sujeto social escolarizado.

Estos antecedentes permitieron que en 1820 la instrucción como mecanismo civilizatorio regulara la sociedad, admitiéndole aprender a leer

7 La formación discursiva hace referencia a un conjunto de reglas históricas determinadas en el tiempo y en el espacio que figuran relaciones de poder y saber en lo social. 
y escribir, lo cual implicaba la creación de escuelas públicas en función de una masificación de la educación, además de la incorporación de las artes, como cabe notar en uno de los reglamentos orgánicos de la enseñanza pública de 1826:

\section{CONSIDERANDO:}

$1^{\circ}$ Que el país en donde la instrucción está más esparcida, y más generalizada la educación de la numerosa clase destinada a cultivar las artes, la agricultura y el comercio, es el que más florece por la industria, al mismo tiempo que la ilustración general en las ciencias y las artes útiles es una fuente perenne y un manantial inagotable de riqueza y de poder para la nación que las cultiva (Colombia, 1826: 1).

Por lo tanto esta noción de utilidad era una condición sine qua non, al sistema gremial, fomentando la educación de las primeras letras, puesto que:

El establecimiento de escuelas de primeras letras en la primera década republicana fue una de las principales preocupaciones. De acuerdo con las leyes promulgadas en el congreso de Cúcuta, la tarea más urgente que necesitaba la República era la apertura de estas escuelas, la creación de colegios y casas de educación y la preparación de maestros que se encargaran de dichos establecimientos (García Sánchez, 2007: 214).

Por lo tanto, la incorporación de la escuela de las primeras letras involucraría la adopción del sistema de enseñanza mutua desarrollado por Lancaster, que permitiría el mayor bien para el mayor número, debido a que era la opción más barata y eficaz de enseñanza a la gran población de las clases pobres, permitiendo enseñar todo a todos, donde un maestro era capaz de enseñar a 1.000 niños mediante un método que pudiera administrar los tiempos, los cuerpos y las subjetividades.

Esto implicaba un ejercicio continuo de disciplinamiento del cuerpo, la mano, la mirada y la voz, sin descuidar, claro está, el acto de vigilar; por tanto este sistema estaba dirigido a los objetos puesto que sin el modelo no era posible un ejercicio de repetición en donde las palabras regularmente se vinculaban a las cosas, y la relación entre la palabra y el objeto estaba mediada por la mirada. El acto de la atención mantenía en complicidad las palabras y las cosas, como lo hace notar Olga Lucía Zuluaga: 
Mirar al modelo y repetirlo. Ver y aprender. Si se usa del ver es para referirlo al modelo y lo que logra con el ver es grabar en la memoria, fijando la mirada de los niños en los modelos o cuadros. Los cuadros contienen ESCRITO lo enseñado, así que si se usa del ver es para referirlo al modelo; el ver abre la puerta de la memoria. [...] En el sistema de enseñanza mutua las palabras y la voz devuelven la mirada hasta el cuadro donde repasan las palabras; en el sistema de enseñanza por objetos, las palabras deben aprenderse vinculadas a las cosas, ya que las ideas que se forman por el contacto con los objetos, preceden a los signos que las representan, esto es, a las palabras; hacerlo de forma diferente sería violentar el orden de la naturaleza (Zuluaga, 1978: 7-8).

Por lo tanto, el sistema lancasteriano dirigido a las clases pobres permitiría hacer más eficaces los procesos y cumplir con el objetivo de fijar en la memoria del niño aquella relación entre lo visible y las palabras pero, aún más, moralizar y subordinar, siendo el sistema lancasteriano aquel que propiciaba la disciplina, la observación y el aprestamiento a rutinas escolares, donde el dibujo tenía un valor mas bien secundario; sin embargo, cumplía con la función de adiestrar y fijar la atención en las cosas.

\section{E1 adiestramiento de los sentidos: Los manuales de dibujo y la enseñanza objetiva}

Luego del reciente sistema de instrucción pública, se da una suerte de renovación en la educación elemental gracias a la introducción al país de la pedagogía objetiva o intuitiva planteada por Pestalozzi, la cual traza sus fundamentos en el reconocimiento de las sensaciones como fuente de conocimiento; por tanto, éste puede considerarse el cuarto proceso de apropiación de la Educación Artística, el del sistema de enseñanza objetiva o intuitiva, que basaba sus planteamientos en la intuición, la percepción inmediata, una educación de los sentidos que cobraría importancia en la formación de la infancia. Dicho sistema se apropia en el contexto colombiano mientras se implementaba el sistema lancasteriano. Este nuevo sistema se hace visible con la publicación de varios manuales enfocados a los maestros — tal como lo anota Olga Lucía Zuluaga - en 1845, cuando aparece el Manual de Enseñanza Mutua de las Primeras Letras, impulsado por José María Triana, así como el 'Manual para el educador primario’ de 1846, en el cual se indica el método intuitivo:

El método intuitivo se propone comunicar conocimientos ofreciendo a la vista los objetos del mundo visible o sus imágenes, haciendo 
sensibles, por figuras hasta las ideas abstractas. Por medio de él los niños adquieren una inteligencia clara de las diferentes especies de animales, de plantas, de las piedras, de las artes, de la unidad, de la forma de los cuerpos, etc. (Triana, 1845: 53).

Tales planteamientos —en función de promover los sentidos mediante la intuición sensible_- es quizá la síntesis del pensamiento de Pestalozzi, donde la intuición es el medio para comprender la naturaleza. Estas ideas de Pestalozzi luego vendrían a fundamentar el sistema de instrucción colombiano, siendo entonces esto el antecedente a una modernización de la educación, pero sobre todo la constitución de una tecnología de saber en función del conocimiento técnico científico, razón por la cual el sistema de instrucción podría ofrecer herramientas orientadas para que los niños pudieran ordenar el mundo, y de esta forma orientar la percepción de éstos, no ya como un sistema cuidadoso de vigilancia y memorístico, sino como un sistema en el cual la intuición permitía ver las cosas un régimen visual empírico - para ordenarlo. Así, la pedagogía pestalozziana fue apropiada como símbolo político y como tecnología práctica para la formación de ese nuevo tipo de hombre moderno; observador del mundo, positivo y, en lo posible, laico (Saldarriaga, 2003: 36).

Sin duda, la apropiación de la pedagogía pestalozziana en Colombia, requería del uso de manuales donde se instituyeran prácticas escolares en función de la formación en la mirada y la atención de los niños, pero sobre todo, bajo un interés particular en el adiestramiento de los sentidos. Lo anterior implicó la implementación de manuales escolares, la creación de escuelas de artes y oficios y la implementación de un sistema de enseñanza de las artes en las universidades, el cual se venía gestando desde el reglamento orgánico de 1826.

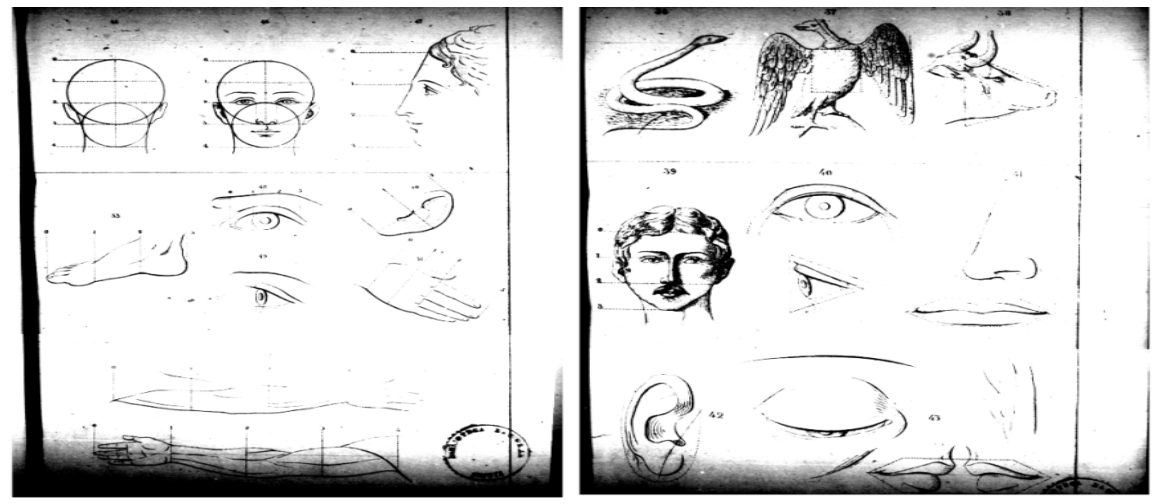

Figura 1. Ejercicios de dibujo geométrico. En: Elementos de dibujo lineal, sombra y perspectiva: fundado en los principios de geometría y escrito (1850). 
De esta manera, la educación pública fundamentada en propósitos manufactureros para la industria, conllevaría a la escolarización de una buena parte de la población infantil en el país, lo que implicaba la fundación de nuevos colegios tanto públicos como privados, además del fortalecimiento de las escuelas normales a través de la incorporación del método de enseñanza objetiva. Los propósitos del método fueron esbozados en las ideas utópicas radicales consignadas en la reforma de 1870 bajo el nombre de Decreto Orgánico de Instrucción Pública Primaria (DOIP), el cual buscaba constituir un sistema público para la educación primaria, junto con una formación de maestros normales, cuyo propósito fuese el de fomentar una libertad en la enseñanza e insistir en un método que fuese libre, enfocado a la inteligencia del niño y, en lo posible, distanciado de métodos memorísticos, como también de un interés por inculcar lo moral sobre lo religioso.

Es así que se hace evidente un claro interés por la formación de un niño "activo", desprendido de un ejercicio memorístico y repetitivo, que conllevó a optar por la implementación del método intuitivo y sensorial de Pestalozzi que se incluye en manuales escolares promovidos por el (DOIP). Dicho sistema no sólo incluía la educación elemental sino también la media y universitaria, donde en cada uno de estos niveles se determinarían los criterios y fines necesarios para la educación del país.

Así la imagen en la escolarización cumplió con la función de promover principios morales, científicos, artísticos, y adicionalmente para llevar las imágenes de un mundo normalizado a través de la representación, buscando instalar en el pensamiento de los niños formas regularizadas del contexto y la industria, como sucedía en el Orbis Sensualium Pictus de Amos Comenio, donde el texto junto con la ayuda de la imagen serían esenciales para conocer el mundo. Por este motivo se encuentra que mediante la enseñanza objetiva se buscaba desarrollar las facultades intelectuales, la percepción, donde era indispensable la formación por vía de los sentidos, que le permitiera guiar la percepción del niño partiendo desde las imágenes externas a las internas. Pestalozzi "consideró como el valor fundamental la claridad cognoscitiva basada en la experiencia, es decir, en la "intuición" efectiva de las cosas. En oposición a los sistemas de enseñanza puramente verbalistas de su tiempo, Pestalozzi reivindica los derechos de la directa aprehensión sensible de los objetos" (Abbagnano, 2008: 472). 
En ese sentido aparece el interés por la enseñanza de las artes, en especial del dibujo, que comienza a verse como un área fundamental en la escuela, por tal razón, se le dedica un tiempo específico en la organización escolar. La enseñanza del dibujo en la distribución curricular de las escuelas benefició a otras asignaturas que lo tomaron como forma para la ilustración de los conocimientos enseñados, y como mecanismo para la ejercitación y refinación del uso de la mano, el cuerpo y la mirada. Esta forma de ser del dibujo escolar mediado por las ideas de la enseñanza objetiva estableció formas de aprendizaje que llevaban al alumno por un conocimiento propedéutico del dibujo, así se fragmentó con el fin de acercarlo a la escuela de manera regulada y determinada por el nivel de escolarización.

Según lo anterior, la enseñanza del dibujo como apoyo a otras asignaturas, bajo el fundamento del $\mathrm{ABC}$, permitió también el reconocimiento y representación tanto de los objetos y personajes extranjeros como de los más inmediatos en el contexto de las ciudades y pueblos, de esta forma la práctica del dibujo que ejercitaba la mano y la mirada necesitó de ejercicios de mimesis.

De esta forma la enseñanza de las técnicas artísticas tenía un significativo interés por ejercitar la mirada y al mismo tiempo delimitar el conocimiento del mundo mediado por aquello que podía ser observable. En ese sentido la visualidad se convirtió en un saber establecido de la enseñanza que se instaló en la escuela a través de prácticas en donde se utilizaron imágenes como medio para la ilustración del conocimiento de la ciencia, como forma de conocimiento del mundo y como materialización del universo de la fe.

\section{Conclusiones}

Se evidencia la coexistencia de discursos que lograron legitimar, conformar, circular, fusionar, apropiar e institucionalizar la Educación Artística en Colombia; resaltando así las estrategias y métodos para la consolidación de proyectos extranjeros emergentes que dominaron en períodos históricos de nuestro país, evidenciando los intereses utilitarios, económicos y civilizatorios.

La modernidad le asignó a la Educación Artística labores especiales, las cuales no solo cubrían la necesidad de enseñar la práctica del arte, sino la de 
establecer en la escuela un tipo de visualidad, esto atribuido a la aparición de tres regímenes escópicos: el cartesiano, el empírico y el barroco, que permearon la escuela e hicieron de la imagen un recurso necesario para la enseñanza.

Se evidencia cómo la Educación Artística aparece en Colombia con el interés de apropiar el proyecto moderno de la Ilustración, en medio de tensiones políticas y sociales de la sociedad colonial de finales del siglo XVIII e inicios del XIX. En este contexto se muestra cómo el interés del discurso de Campomanes sobre la organización de la educación popular y los gremios conserva un especial interés en la estructuración de un sistema productivo con intereses económicos. Basados en este discurso se presenta la relación del dibujo como posibilidad para el adiestramiento y perfección de los resultados artesanales, así como mecanismo para evitar la ociosidad. Asimismo se logra establecer la relación del dibujo y la Educación Artística como saberes útiles para la consolidación de los sistemas industrializados y científicos, como el caso de la expedición botánica; de esta forma se demuestra que la racionalización de aspectos sensibles declarados hasta ese momento para el arte tenía importantes compromisos con la mirada científica y económica de la época. Finalmente se expone cómo a mediados del siglo XIX se establece un interés por la enseñanza del dibujo con fines industriales con el interés de objetivar la realidad; estas prácticas se desarrollaron a partir de un ejercicio mimético como método producto de la apropiación del sistema pestalozziano para la educación de la mirada y la mano, donde se legitimaron formas de belleza presentadas en los "modelos".

En algunos momentos la Educación Artística centró la atención sobre la enseñanza del dibujo y éste se convirtió en una disciplina escolar, respondiendo efectivamente a las preocupaciones sociales, políticas y culturales, relaciones de poder y de saber.

\section{Referencias}

Abbagnano N., V. (2008). Historia de la pedagogía. México: Fondo de Cultura Económica.

Aguirre L., E. (2010). Enseñar con texto e imágenes. Una de las aportaciones de Juan Amós Comenio. Recuperado el 25 de noviembre de 2010 de http://redie. uabc.mx/vol3no1/contenido-lora.html 
Álvarez, G. A. (1995). Y la escuela se bizo necesaria. En busca del sentido actual de la escuela. Bogotá: Magisterio - Colección mesa redonda.

Bermúdez A., J. (2005). Génesis y evolución del Dibujo como disciplina básica en la segunda enseñanza. Murcia: Universidad de Murcia.

Campomanes, P. (1775). Discursos sobre la educación popular de los artesanos y su fomento. Madrid: Imprenta de D. Antonio Desancha.

Colombia (1826). Ley y reglamentos orgánicos de la enseñanza pública en Colombia acordados en 1826 _ 6 años de la independencia'. Miscelánea 1413 [95]. Bogotá: Imprenta de Manuel María Viller-Calderón.

De Pedro Robles, A. (2009). 'Pedro Rodríguez de Campomanes y el discurso sobre la educación popular’. SOTO A., D. Ilustración y educación: comentario de textos. Tunja: Doce calles.

Efland D., A. (2002). Una historia de la educación del arte. Tendencias intelectuales y sociales en la enseñanza de las artes visuales. Barcelona: Paidós.

FOUCAULT, M. (2005). Vigilar y castigar. México: Siglo XXI. (2007). La bistoria de la sexualidad, la voluntad de saber. México: Siglo del Hombre Editores.

García S., B. Y. (2007). De la educación. Bogotá: Ediciones Universidad Distrital.

Orlando, C. \& Noguera, C. E. (2002). 'La educación en la Santafé Colonial'. Historia de la educación en Bogotá [Tomo I]. Bogotá: Panamericana.

Saenz, O. J.; Saldarriaga, Ó. \& Ospina, A. (1997). Mirar la infancia: pedagogía, moral y modernidad en Colombia, 1903-1946. Bogotá: Ediciones Uniandes.

Saldarriaga, O. (2003). Del oficio del maestro. Prácticas y teorias de la pedagogía moderna en Colombia. Bogotá: Magisterio.

STAFFORD, B. M. (1997). 'Body criticism. Imaging the unseen in enlightenment art and medicine'. Martínez M., J. La ilustración como categoría. Una teoría unificada sobre arte y conocimiento. Girón: Ediciones Trea S. L.

Touraine, A. (2000). Crítica de la modernidad. México: Fondo de Cultura Económica.

Triana, J. M. (1845). 'Manual del profesor primario'. Manual de enseñanza mutua para las escuelas de primeras letras, redactado por José Marta Triana, comisionado especialmente al efecto por el Director General de Instrucción Pública. Bogotá: Impreso por J. A. Cualla.

Zuluaga, O. L. (1978). Colombia: Dos modelos de su práctica pedagógica durante el siglo XIX. Avance de investigación. Medellín: Universidad de Antioquia. 